\title{
PATOFISIOLOGI BARODONTALGIA PADA PENERBANGAN SIPIL
}

\section{(PATHOPHYSIOLOGY OF BARODONTALGIA ON CIVIL AVIATION)}

\author{
Cecilia Monika Shinta Nova Andarmawanti*, Achmad Hidayat**, Nurtami Soedarsono*** \\ *Mahasiswa Program Magister Ilmu Kedokteran Gigi Dasar-Forensik Kedokteran Gigi \\ Fakultas Kedokteran Gigi, Universitas Indonesia \\ ***Departemen Ilmu Kedokteran Komunitas Program Studi Spesialis Kedokteran Penerbangan \\ Fakultas Kedokteran, Universitas Indonesia \\ ***Program Studi Magister Ilmu Kedokteran Gigi Dasar \\ Fakultas Kedokteran Gigi, Universitas Indonesia \\ Jl. Salemba Raya No.4, Jakarta Pusat
}

\begin{abstract}
Barodontalgia is a dental pain caused by the changes in barometric pressure due to altitude changes. During the flight in civil aviation, pressure changes could cause pain in tooth. Barodontalgia is a symptom rather than a pathological condition and closely associated with pathological conditions existing teeth. Most of the common oral pathologies were reported as possible sources of barodontalgia including dental caries, pulpitis, pulp necrosis, defective tooth restoration, apical periodontitis and impacted tooth, but the pathophysiology is not fully understood yet. Intensity and time of onset barodontalgia vary among person depending on existing oral pathological condition and the current phase of flight (ascent, cruise or descent). This article reviews the definition, etiology and pathophysiology of barodontalgia as well as the relationship between the pathophysiology of each pathological condition with changes in pressure occuring during the flight.
\end{abstract}

Key words: barodontalgia, civil aviation, dental pain, pathophysiology, pressure change

\begin{abstract}
Abstrak
Barodontalgia merupakan nyeri gigi yang disebabkan oleh perubahan tekanan barometrik akibat perubahan ketinggian. Sebagai individu yang biasa hidup didarat, saat terbang diketinggian selama penerbangan sipil akan memungkinkan mengalami keluhan nyeri pada gigi akibat perubahan tekanan barometrik. Barodontalgia adalah suatu gejala pada suatu kondisi patologis, dan pada kebanyakan kasus merupakan hal yang erat hubungannya dengan kondisi patologis gigi yang sudah ada sebelumnya. Kondisi patologis yang paling sering dilaporkan sebagai penyebab barodontalgia adalah karies gigi, pulpitis, nekrosis pulpa, adanya tambalan yang rusak atau tidak sempurna serta impaksi gigi molar ketiga, namun patofisiologi barodontalgia belum sepenuhnya dipahami. Intensitas dan saat terjadinya barodontalgia dapat berbeda-beda pada tiap individu tergantung pada kondisi patologis yang ada dan fase saat terbang (ascent, descent atau cruise). Dalam artikel ini akan mengulas mengenai pengertian,etiologi dan patofisiologi barodontalgia serta hubungan antara faktorfaktor patofisiologis dari gigi penyebab barodontalgia dengan perubahan tekanan yang terjadi pada ketinggian selama penerbangan sipil.
\end{abstract}

Kata kunci: barodontalgia, nyeri gigi, patofisiologi, penerbangan sipil, perubahan tekanan

\section{PENDAHULUAN}

Beberapa tahun terakhir ini telah terjadi peningkatan penggunaan transportasi udara oleh masyarakat dengan alasan faktor biaya yang cukup terjangkau serta efisiensi waktu. Pada saat mengggunakan transportasi udara individu mungkin akan mengalami keluhan akibat perubahan lingkungan eks- ternal seperti perubahan tekanan udara. Perubahan tekanan udara yang terjadi saat penerbangan dapat menimbulkan keluhan nyeri disebabkan adanya pengembangan gas yang tertahan di dalam rongga tubuh, salah satunya gigi.

Nyeri gigi pada saat terjadi perubahan tekanan udara di ketinggian pada saat terbang disebut barodontalgia. Secara umum barodontalgia didefinisikan 
sebagai nyeri gigi yang disebabkan oleh perubahan dalam tekanan atmosfer lingkungan. ${ }^{1}$ Gejala utamanya adalah rasa nyeri menusuk ataupun tumpul yang muncul tiba-tiba dengan intensitas yang tinggi. ${ }^{2}$ Barodontalgia merupakan gejala dari suatu kondisi patologis dan bukan merupakan suatu diagnosis. ${ }^{3}$ Sebagian besar kondisi patologis dalam mulut seperti karies gigi, restorasi gigi yang rusak, peradangan pulpa, nekrosis pulpa, periodontitis apikalis, dan gigi impaksi ${ }^{4-6}$, membuat gigi rentan terhadap barodontalgia.

Tujuan penulisan artikel ini adalah untuk menjelaskan patofisiologi barodontalgia pada penerbangan sipil. Dalam artikel ini, akan diuraikan hubungan antara patofisiologi gigi penyebab barodontalgia dengan perubahan tekanan yang terjadi di ketinggian. Dengan berkembangnya bidang transportasi udara, dokter gigi akan banyak menjumpai masalah nyeri gigi yang berkaitan dengan perubahan lingkungan saat terbang sehingga dokter gigi harus memiliki pengetahuan, memahami etiologi dan patofisiologi barodontalgia. Hal ini penting untuk membantu dokter gigi dalam menegakkan diagnosa dan mencari gigi penyebab timbulnya barodontalgia, sehingga dapat disusun rencana perawatan gigi yang tepat.

\section{PERUBAHAN LINGKUNGAN PADA PE- NERBANGAN}

Lingkungan selama terbang di ketinggian berbeda dengan lingkungan saat di darat. Semakin jauh dari permukaan bumi maka semakin rendah suhu, tekanan udara, dan suplai oksigen. Semakin naik dari permukaan bumi, suhu akan terus turun sebesar $3,56^{\circ} \mathrm{F}$ $\left(1,98{ }^{\circ} \mathrm{C}\right)$ tiap 1.000 kaki (305 meter). ${ }^{7}$ Pada ketinggian $35.000 \mathrm{kaki}$, suhu akan konstan $-55{ }^{\circ} \mathrm{C}$ sampai pada ketinggian 70.000 kaki. Pada saat dalam penerbangan, juga terjadi penurunan tekanan udara yang akan menyebabkan penurunan tekanan oksigen. Dengan turunnya tekanan oksigen di ketinggian, maka tekanan oksigen di dalam alveoli (paru-paru) juga akan turun, sehingga suplai oksigen pada jaringan menjadi tidak adekuat. ${ }^{8}$

Gaya gravitasi bumi mempengaruhi kerapatan udara dipermukaan bumi, sehingga semakin jauh dari permukaan bumi, udara akan semakin renggang. Saat di ketinggian, dengan semakin renggangnya udara maka tekanan udaranya pun semakin kecil. ${ }^{7}$ Berdasarkan International Standard Atmosphere (ISA), tekanan rata-rata atmosfer adalah sebesar 29,92 inci air raksa (inches $\mathrm{Hg}$ ), atau 760 milimeter air raksa $(\mathrm{mm} \mathrm{Hg}){ }^{7}$

\section{PENGARUH PERUBAHAN TEKANAN UDARA DALAM PENERBANGAN SIPIL TERHADAP TERJADINYA BARODONTALGIA}

Barodontalgia merupakan rasa nyeri pada gigi yang diakibatkan oleh perubahan udara karena peningkatan atau penurunan tekanan udara. ${ }^{6,9,10}$ Barodontalgia memberikan gejala klinis berupa nyeri spontan ketika berada di dalam pesawat pada ketinggian tertentu dan biasanya hilang ketika mencapai zona tekanan normal. ${ }^{9}$

Penerbangan sipil biasanya menggunakan helikopter ataupun pesawat transport komersil yang terbang pada ketinggian 1.500-12.000 meter (5.000-40.000 kaki). Mulai dari permukaan laut sampai sekitar 3.000-3.600 meter (10.000-12.000 kaki), tekanan udara mengalami penurunan dari $760 \mathrm{~mm} \mathrm{Hg}$ hingga $483 \mathrm{~mm} \mathrm{Hg}$. ${ }^{7}$ Untuk mengimbangi penurunan tekanan udara dan membantu mengurangi prevalensi barodontalgia, penerbangan komersil menggunakan sistem kabin bertekanan, sehingga tekanan di dalam kabin diusahakan setara dengan tekanan di luar kabin. Namun, karena tekanan di dalam kabin pesawat hanya setara dengan tekanan pada ketinggian 1.500 hingga 3.000 meter, barodontalgia masih mungkin terjadi selama penerbangan komersil. ${ }^{3}$

Dalam penerbangan sipil terdapat tiga fase terbang yaitu: fase ascent, cruise dan descent. Fase ascent merupakan fase awal setelah lepas landas, saat pesawat terbang naik sampai pada ketinggian tertentu. Fase cruise adalah saat pesawat terbang pada posisi stabil di udara dan terakhir adalah fase descent, pada saat pesawat terbang turun. Perubahan tekanan udara pada fase-fase tersebut mempengaruhi perubahan volume gas dalam tubuh. Perubahan volume gas yang terjadi akibat perubahan tekanan udara sesuai dengan hukum Boyle yang menyatakan bahwa volume gas berbanding terbalik dengan tekanan. 3,11 Pada saat fase ascent, tekanan udara mengalami penurunan sehingga mengakibatkan penambahan volume gas dalam tubuh. Sebaliknya pada saat fase descent, tekanan udara mengalami kenaikan sehingga volume gas dalam tubuh mengalami pengurangan.

Penelitian menunjukkan barodontalgia dalam penerbangan mulai terjadi pada ketinggian sekitar 3.000 meter saat tekanan ambien atmosfer 0,75 atm. ${ }^{12}$ Keluhan barodontalgia yang terjadi di dalam pesawat dilaporkan terjadi pada ketinggian 3.0009.000 meter. ${ }^{2,} 9$ Barodontalgia dilaporkan lebih sering terjadi saat fase ascent dibandingkan saat fase descent. $^{3}$ 


\section{PATOFISIOLOGI KONDISI GIGI PENYEBAB BARODONTALGIA}

Secara umum patofisiologi merupakan studi sistematis dari perubahan fungsional dalam sel, jaringan dan organ yang diakibatkan oleh penyakit atau cedera. ${ }^{13}$ Jaringan tubuh selalu terpapar kondisi yang sering berubah dan berpotensi menjadi rangsangan yang menyebabkan reaksi fisiologis untuk beradaptasi baik berupa cedera atau kematian jarringan. ${ }^{13}$

Gigi termasuk bagian tubuh yang akan mengalami perubahan akibat proses reaksi terhadap rangsangan eksternal, kemudian bermanifestasi sebagai kelainan/penyakit. Jaringan pulpa gigi dapat mengalami cedera atau kematian oleh karena berbagai faktor seperti karies atau rangsangan ekternal (mekanis, kimiawi, termal). ${ }^{14}$ Cedera atau stimulus rangsang yang berbahaya akan menimbulkan reaksi pada sistem vaskularisasi dan persarafan gigi. ${ }^{15}$ Reaksi pada sistem vaskularisasi melibatkan dua pembuluh darah besar dalam sistem pembuluh darah pulpa gigi (arteriol dan venul) berupa vasokonstriksi dan vasodilatasi. ${ }^{15}$ Reaksi pada sistem persarafan pulpa meliputi respons nyeri dari dua jenis serabut saraf sensorik dalam pulpa, yaitu serabut bermielin (serabut A) dan tidak bermielin (serabut C). ${ }^{16}$ Serabut A mencakup baik serabut A-beta dan A-delta. Serabut saraf sen0sorik pulpa gigi berasal dari saraf trigeminal yang masuk ke dalam radikuler pulpa melalui foramen apikal dan bagian midroot dari pulpa. ${ }^{17}$ Terminal serabut saraf dapat ditemukan tepat di dalam pulpa (umumnya serabut C) atau dapat menembus odontoblas dan berakhir tidak jauh di sekitar odontoblas dalam tubulus dentin (umumnya serabut A-delta atau A-beta). ${ }^{17}$

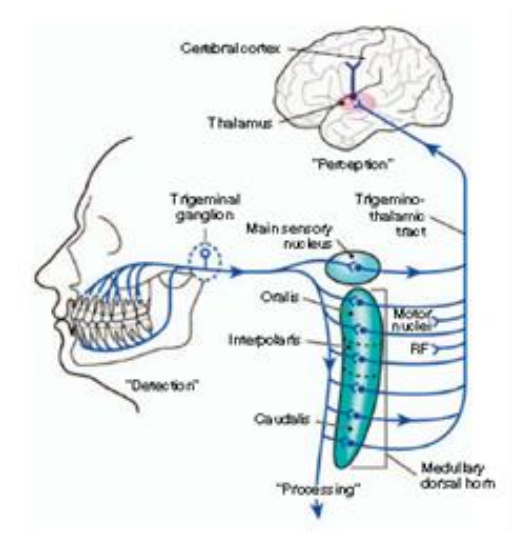

Gambar 1. Ilustrasi skematik jalur transmisi informasi nyeri gigi ${ }^{16}$
Stimulus pada saraf sensorik pulpa gigi akan memulai suatu impuls yang berjalan sepanjang akson pulpa pada cabang maksila atau mandibular dari nervus trigeminus ke ganglion trigeminus, badan sel dari saraf trigeminal yang mengandung neuron berlokasi (neuron tingkat pertama). ${ }^{15}$ Dendrit dari ganglion trigeminus kemudian melintas ke arah pusat dan bersinapsis dengan neuron tingkat kedua di kompleks nukleus trigeminus yang terletak pada basis medula dan ujung atas korda spinalis. ${ }^{15} \mathrm{Se}-$ bagian besar stimulus yang menyebabkan nyeri gigi akan dikonduksikan sepanjang akson yang bersinapsis dengan neuron di bagian spinalis dari kompleks nukleus trigeminus, terutama di nukleus kaudalis. ${ }^{15}$ Informasi yang direkam pada neuron tingkat kedua selanjutnya akan diteruskan ke talamus dan korteks serebral melalui traktus trigeminotalamus dengan hasil akhir berupa persepsi nyeri gigi. ${ }^{15}$ Stimulus pada serabut sensorik saraf A menimbulkan persepsi nyeri tajam menusuk dan stimulus pada serabut saraf C menimbulkan persepsi nyeri tumpul, terbakar dengan sensasi intesitas nyeri yang lebih ringan dibandingkan nyeri serabut saraf $\mathrm{A}^{16}$

Barodontalgia adalah gejala daripada suatu kondisi patologis, dan pada kebanyakan kasus merupakan hal yang erat hubungannya dengan kondisi patologis gigi yang sudah ada sebelumnya. ${ }^{9,10}$ Barodontalgia biasanya merupakan suatu perkembangan dari penyakit sub-klinis oral-maksilofacial yang disebabkan oleh perubahan tekanan udara. ${ }^{6}$ Kondisi patologis gigi yang menyebabkan barodontalgia adalah karies dentin, pulpitis, nekrosis pulpa, periodontitis apikalis, gigi dengan restorasi yang rusak/tidak sempurna dan gigi molar ketiga yang impaksi. . 3,6,10,18,19 $^{-}$

\section{KONDISI PATOLOGIS KARIES DENTIN SEBAGAI PENYEBAB BARODONTALGIA}

Karies dentin merupakan kelanjutan proses karies email yang mencapai dentin. Nyeri dentin timbul akibat rangsangan fisik melalui efek aliran cairan dentin atau akibat pelepasan mediator inflamasi yang mengaktifkan nosiseptor serabut saraf tubulus dentin. ${ }^{20}$ Berdasarkan teori hidrodinamik, stimulus rangsangan akan menyebabkan pergerakan cairan dalam tubulus dentin. ${ }^{21}$ Pergerakan cairan mengaktifkan ujung saraf pada dentin atau pulpa. ${ }^{21}$ Pergerakan cairan ke luar maupun ke dalam akan mengakibatkan distorsi ujung saraf di daerah pleksus saraf subodontoblas (pleksus raschkow) yang akan menimbulkan impuls saraf dan sensasi nyeri. ${ }^{15}$ 


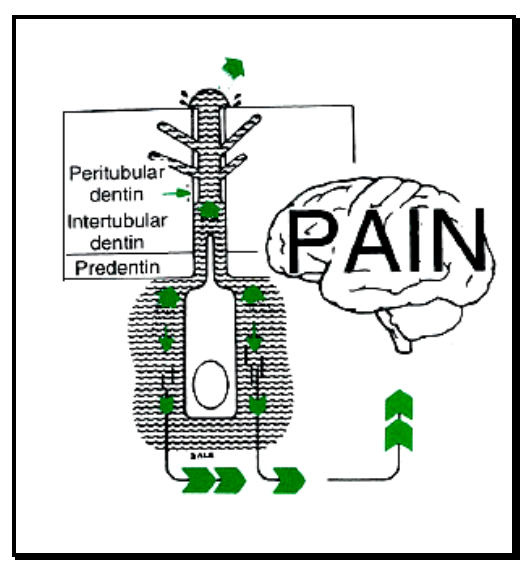

Gambar 2. Gambaran skematik mekanisme nyeri dentin teori hidrodinamik ${ }^{15}$

\section{KONDISI PATOLOGIS PULPITIS SEBAGAI PENYEBAB BARODONTALGIA}

Cedera pulpa dapat disebabkan oleh bakteri dan toksinnya, iritasi mekanis, kimia dan termal. ${ }^{14,15}$ Faktor bakteri adalah yang paling utama dalam etiologi pulpitis. ${ }^{22}$ Toksin bakteri akan berpenetrasi melalui tubulus dentin dan mencapai pulpa telebih dahulu baru selanjutnya diikuti oleh invasi bakteri ke dalam pulpa. ${ }^{17}$

Reaksi peradangan pulpa melibatkan komponen vaskular dan selular dalam pulpa. ${ }^{15}$ Perubahan vaskular berupa vasokonstriksi kemudian diikuti oleh vasodilatasi pembuluh darah yang menyebabkan peningkatan aliran darah dan eksudat serta permeabilitas vaskular. ${ }^{15}$ Jaringan pulpa tidak dapat membengkak secara bebas karena berada dalam dinding yang keras dan kaku, sehingga peningkatan cairan interstitial dalam pulpa akan menyebabkan peningkatan tekanan lokal di dalam pulpa yang mengalami cedera. ${ }^{15}$ Kompensasi dilakukan oleh jaringan untuk menjaga tekanan jaringan tetap dalam batas normal dengan cara meningkatkan tekanan intraluminal kapiler lokal. ${ }^{15}$ Aliran darah ke daerah cedera dikurangi melalui mekanisme anastomosis arterivena, dengan membelokan aliran arah dari arteriol ke kapiler menjadi ke venul. Apabila penyebab cedera dihilangkan maka secara perlahan aliran darah akan normal kembali. ${ }^{15}$ Namun bila cedera dibiarkan, maka luas kerusakan pulpa akan bertambah dan akan terjadi nekrosis pulpa. ${ }^{15}$ Komponen selular yang terlibat adalah sel-sel inflamasi kronis (makrofag, limfosit dan sel plasma). ${ }^{15}$ Dengan adanya bakteri dan toksinnya di dalam dentin maka jaringan pulpa akan terinfiltrasi secara lokal. ${ }^{15}$ Pada waktu karies meluas ke arah pulpa, karakter dan intensitas infiltrat akan berubah. ${ }^{15}$ Jika pulpa terbuka, jaringan pulpa akan diinfiltrasi secara lokal oleh leukosit polimorfonukleus (PMN) membentuk suatu daerah nekrosis liquifaksi dan menjadi tempat menetap koloni bakteri. Dalam pulpa gigi yang meradang, ujung nosiseptif mendeteksi keberadaan mediator inflamasi. ${ }^{23}$ Apabila perantara inflamasi mencapai konsentrasi cukup untuk mengaktifkan reseptor, maka neuron nosiseptif akan menjadi aktif menghantarkan sinyal ke sistem saraf pusat. ${ }^{23}$

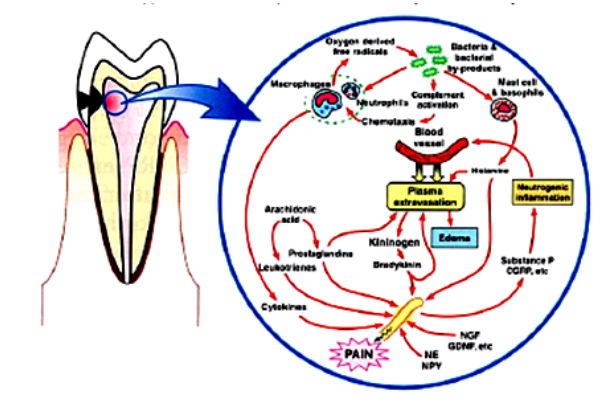

Gambar 3. Mekanisme stimulasi nyeri pada kondisi pulpitis $^{17}$

\section{KONDISI PATOLOGIS NEKROSIS PULPA SEBAGAI PENYEBAB BARODONTALGIA}

Reaksi lanjut pulpitis ireversibel adalah nekrosis likuifaksi. ${ }^{15}$ Apabila eksudat yang terjadi selama pulpitis ireversibel dikeluarkan maka proses kerusakan dapat dihentikan dan pulpa di bagian akar tetap vital (nekrosis pulpa sebagian). ${ }^{15}$ Namun apabila kondisi pulpitis ireversibel dibiarkan, maka proses likuifaksi akan berlanjut dan keseluruhan pulpa menjadi nekrosis. ${ }^{15}$ Studi histologis menunjukkan tidak terdapat tingkat persarafan yang tinggi pada gigi non vital, sehingga diperkirakan penyebab rasa nyeri pada nekrosis pulpa timbul karena pengalihan bahan noksious ke terminal saraf pada jaringan periapikal. $^{16}$

\section{KONDISI PATOLOGIS PERIODONTITIS APIKALIS SEBAGAI PENYEBAB BARO- DONTALGIA}

Periodontitis apikalis biasanya melibatkan nekrosis pulpa akibat pulpitis ireversibel. ${ }^{22}$ Setelah terjadi kerusakan keseluruhan jaringan pulpa, bakteri serta toksinnya dan iritan lainnya dari pulpa yang nekrotis akan berdifusi ke periapikal sehingga timbul lesi inflamasi di daerah periapikal. ${ }^{15}$ Pembentukan respons inflamasi ini merupakan upaya untuk mencegah penyebaran infeksi ke jaringan periapikal. ${ }^{17}$

Periodontitis apikalis dapat juga disebabkan oleh bakteri dan toksinnya yang berasal dari biofilm pada permukaan akar dari poket periodontal. ${ }^{17}$ Toksin bakteri ini masuk ke dalam pulpa melalui saluran asesoris lateral atau difusi melalui tubulus dentin. ${ }^{17}$ 
Pada kondisi ini, gigi mengalami periodontitis apikalis tetapi tetap vital. ${ }^{17}$ Mekanisme nyeri pada kondisi inflamasi periradikular dimulai dengan aktivasi mekanoreseptor nosiseptif periradikular akibat tekanan dalam tulang oleh bakteri dan toksinnya serta perantara inflamasi yang kemudian dihantarkan ke sistem saraf pusat. ${ }^{15}$

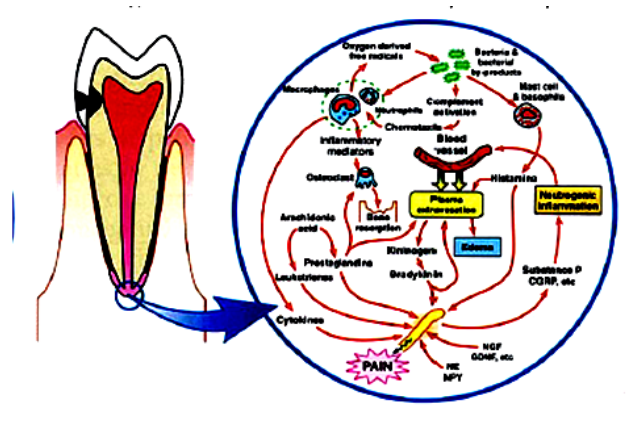

Gambar 4. Mekanisme stimulasi nyeri pada kondisi periodontitis apikalis $^{17}$

\section{KONDISI PATOLOGIS RESTORASI YANG RUSAK/TIDAK SEMPURNA SEBAGAI PE- NYEBAB BARODONTALGIA}

Restorasi pada gigi dilakukan untuk menghentikan proses karies sebagai upaya melindungi pulpa terhadap cedera, sehingga kematian pulpa dapat dihindari. Namun restorasi tidak dengan sendirinya dapat mencegah cedera pulpa, karena apabila restorasi tersebut tidak sempurna atau rusak maka akan terjadi kebocoran yang dapat menyebabkan peradangan pulpa. Kebocoran restorasi menyebabkan terjadinya celah antara bahan restorasi dengan dentin, sehingga bakteri dan toksinnya dapat masuk ke dentin. ${ }^{14,15}$ Bakteri dan toksinnya tersebut kemudian dapat masuk ke dalam pulpa dan menyebabkan cedera pulpa. ${ }^{15,17}$

\section{KONDISI PATOLOGIS IMPAKSI GIGI MO- LAR KETIGA SEBAGAI PENYEBAB BARO- DONTALGIA}

Berdasarkan urutan erupsi, gigi molar ketiga rahang atas dan bawah mengalami erupsi pada usia 17-21 tahun ${ }^{22}$ dan masih dapat berlanjut sampai usia 25 tahun. ${ }^{24}$ Pada beberapa individu, terjadi penyimpangan dari urutan normal erupsi yang ditunjukkan dengan adanya gangguan erupsi gigi molar ketiga atau yang dikenal dengan impaksi molar ketiga. Impaksi didefinisikan sebagai gigi yang tidak erupsi atau erupsi hanya sebagian, karena terhalang oleh gigi lain, tulang atau jaringan lunak sehingga tidak mungkinkan untuk erupsi secara lengkap. ${ }^{22}$ Nyeri pada kondisi impaksi gigi molar ketiga dapat disebabkan akibat tekanan konstan pada bagian belakang gigi molar kedua yang berada di depan gigi impaksi tersebut atau akibat peradangan gingiva sekitar gigi molar ketiga yang mengalami impaksi. ${ }^{22}$

\section{PEMBAHASAN}

Pulpitis dengan atau tanpa peradangan periapikal dilaporkan sebagai penyebab utama barodontalgia. ${ }^{3,}$

${ }^{6}$ Barodontalgia pada kondisi patologis pulpitis dirasakan pada saat terbang naik (fase Ascent). Pada saat terbang naik, tekanan udara eksternal menjadi berkurang dan mengakibatkan pengembangan gas dalam pulpa sehingga merangsang pulpa yang dalam kondisi meradang. Pengembangan gas dalam pulpa yang tertutup akan mengaktifkan nosiseptor serabut saraf A pada pertemuan dentin-pulpa atau serabut saraf $\mathrm{C}$ dalam pulpa, tergantung pada kondisi pulpitisnya (reversible atau ireversible). Hal ini yang menyebabkan rasa nyeri barodontalgia pada kondisi pulpitis dapat berupa nyeri tajam ataupun nyeri tumpul.

Kondisi patologis karies dentin dilaporkan dapat menyebabkan barodontalgia. Pada saat terbang naik (fase ascent) terjadi perubahan tekanan udara yang mempengaruhi pergerakan cairan keluar dari dalam tubulus dentin. Pergerakan cairan dalam tubulus dentin akan menstimulasi nosiseptor serabut saraf A pada kompleks dentin-pulpa yang kemudian mengubah stimulus menjadi impuls yang dihantarkan ke sistem saraf pusat dan dipersepsikan sebagai nyeri tajam. Karies dentin disertai peradangan yang sudah mencapai pulpa juga dilaporkan merupakan penyebab barodontalgia. ${ }^{12}$ Pada kondisi karies dentin dalam, toksin bakteri akan masuk dan menyebabkan peradangan pulpa. Barodontalgia pada kondisi karies dentin dalam dengan peradangan telah mencapai pulpa dirasakan pada saat terbang naik akibat pengembangan gas dalam pulpa menstimulasi nosiseptor serabut saraf A.

Barodontalgia pada kondisi patologis nekrosis pulpa diinduksi oleh perubahan tekanan dirasakan pada saat terbang turun (fase descent). Pada saat fase descent, udara masuk ke dalam pulpa. Masuknya udara ke dalam pulpa kemudian menekan isi pulpa dan saluran akar terdorong ke dalam tulang rahang sehingga menyebabkan nyeri. ${ }^{3}$ Nyeri yang dirasakan merupakan nyeri tumpul karena yang tereksitasi adalah serabut saraf $C$.

Barodontalgia pada kondisi periodontitis apikalis dirasakan pada saat terbang turun (fase descent) akibat meningkatnya tekanan di dalam lesi tulang rahang. ${ }^{18}$ Dengan meningkatnya tekanan dalam lesi tulang rahang akan mengaktifkan serabut saraf $\mathrm{C}$ serta serabut mekanoreseptor di ligamen periodontal 
sehingga menimbulkan impuls yang kemudian dipersepsikan sebagai nyeri menetap yang parah.

Pada kondisi gigi dengan restorasi yang tidak sempurna atau mengalami kebocoran mencapai dentin, perubahan tekanan udara dapat menyebabkan barodontalgia. Perubahan tekanan udara mempengaruhi pengembangan gas yang ada di antara gigi dan restorasi serta memicu pergerakan cairan dalam tubulus dentin. Cairan mulut akan tersedot dari dalam tubulus dentin dan mengaktifkan ujung nosiseptor serabut saraf A yang kemudian menjadi impuls yang dihantarkan ke sistem saraf pusat dan dipersepsikan sebagai nyeri. ${ }^{3,18}$ Apabila kebocoran restorasi menyebabkan bakteri dan toksinnya masuk sampai ke dalam pulpa yang vital maka dapat menyebabkan peradangan pulpa. Kondisi seperti ini juga dapat menyebabkan barodontalgia.

Impaksi gigi molar ketiga ditemukan dapat menyebabkan gejala barodontalgia. ${ }^{18}$ Barodontalgia pada kondisi impaksi gigi molar ketiga disebabkan oleh karena peningkatan tekanan di antara tulang didalam ruang di bawah gigi molar ketiga impaksi tersebut pada saat terbang turun (fase descent).

Dapat disimpulkan bahwa terdapat dua faktor penyebab barodontalgia pada penerbangan sipil yaitu perubahan tekanan lingkungan berhubungan dengan fase saat terbang (ascent/descent) dan adanya kondisi patologis dalam rongga mulut, yang apabila terdapat keduanya maka akan meningkatkan resiko barodontalgia. Intensitas dan saat terjadinya nyeri barodontalgia berhubungan erat dengan kondisi patologis yang ada dalam rongga mulut, sehingga dapat berbeda-beda pada setiap individu.

Dengan diketahuinya patofisiologi barodontalgia pada penerbangan sipil, diharapkan dapat meningkatkan upaya pencegahan dan pengobatan keluhan pada gigi yang berhubungan dengan perubahan lingkungan yang dialami dalam penerbangan Pemeriksaan gigi secara rutin dilakukan agar dapat mendeteksi secara dini kondisi patologis yang ada pada gigi untuk menghindari terjadinya barodontalgia pada penerbangan sipil.

\section{Daftar Pustaka}

1. Gunston B. The cambridge aerospace dictionary. In: Jane's Information Group, eds: Cambridge: Cambridge University Press; 2004: 17.

2. Santiago MdMG, Marques AM-S, Fernandez PB. Incidence of barodontalgias and their relation to oral/dental condition in personnel with responsibility in military flight. Med Oral 2004; 9: 92-105.

3. Zadik Y. Barodontalgia. JOE 2009; 35(4): 481-83.

4. Zadik Y. Barodontalgia: what we have learned in the past decade? Oral Surg Oral Med Oral Pathol
Oral Radiol Endod 2010;109: e65-e69.

5. Zadik Y. Barodontalgia due to odontogenic inflamation in the jawbone. Aviat Space Environ Med 2006; 77: 864-66.

6. Zadik Y. Aviation dentistry: current concepts and practice. Br Dent J 2009; 206: 11-16.

7. Reinhart RO. Basic flight physiology. $3^{\text {rd }}$ ed. New York: McGraw-Hill eBooks; 2008: 36-8, 70-4.

8. George W. Casey J. Aeromedical training for flight personnel. In: Department AH, eds. Washington, DC; 2009: 15-41, 63-74.

9. Al-Hajri W, Al-Madi E. Prevalence of barodontalgia among pilots and divers in saudi arabia and kuwait. Saudi Dent J 2006;18(3):134-40.

10. Tarun KG, Shrivastava TV. Barodontalgia: a clinical entity. J Oral Health Comm Dent 2012; 6(1): 18-20.

11. Whitton LRC. Flight Surgeon's Guide. Vol 1. Brooks AFB, Texas: USAF School of Aerospace Medicine; 1992: 61-9.

12. Robichaud R, McNally ME. Barodontalgia as a differential diagnosis: symptoms and findings. J Can Dent Assoc 2005; 71(1): 39-42.

13. Kathryn L. McCance, Sue EH. Pathophysiology : the biologic basic for disease in adult and children: St Louis: Elseiver Mosby; 2006: 198-9.

14. Graham JM, Hume WR. Preservation and restoration of tooth structure. $2^{\text {nd }}$ ed: Knowledge Books and Software; 2005: 11-34.

15. Walton RE, Torabinejad M. Endodontics : principle and practice. $4^{\text {th }}$ ed: Elsevier Inc; 2009: 1-93.

16. Kenneth M. Hargreaves, Stephen Cohen. Cohen's Pathways of the pulp. $10^{\text {th }}$ ed. St.Louis: Elsevier Inc; 2011: 460-690.

17. Ingle JI, Bakland LK, Baumgartner JC. Ingle's Endodontics 6: People's Medical Publishing House Shelton, Connecticut; 2008: 376-502.

18. Zadik Y, Chapnik L, Goldstein L. In-flight barodontalgia: analysis of 29 cases in military aircrew. Aviat Space Environ Med 2007; 78: 593-96.

19. Rai B, Kaur J, Catalina M, Anand SC. Prevalence of barodontalgia in indian origin pilots: a survey. J Stomat Occ Med 2010; 3(2): 115-17.

20. Kenneth M. Hargreaves, Goodis. HE. Seltzer and Bender's dental pulp: Quintessence Publishing Co, Inc; 2002: 95-199.

21. Lund JP, Lavigne GJ, Dubner R, Sessle BJ. Orofacial pain : from basic science to clinical management: Quintessence Publishing Co, Inc; 2001: 3-45.

22. Andersson L, Kahnberg K-E, Pogrel MA. Oral and maxillofacial surgery: Willey-Blackwell; 2010: 259-67, 497-500.

23. Fouad AF. Endodontic microbiology.Iowa: WileyBlackwell; 2009: 212-24.

24. Hupp JR, Ellis E, Tucker MR. Contemporary oral and maxillofacial surgery. $5^{\text {th }}$ ed. St Louis: Elsevier Inc; 2008: 143-48. 